\title{
The Adhesion Force Change of an Experimental Road Vehicle
}

Petr Jilek (0000-0002-3863-2252), Jan Berg (0000-0001-6644-9917)

University of Pardubice, Faculty of Transport Engineering, Studentská 95, 53210 Pardubice. Czech Republic. Email: petr.jilek@upce.cz, st45934@student.upce.cz

The Article deals with the controlled influence of the adhesive force in contact of the road vehicle's wheel with the road. The first section shows how the adhesive force is reduced. The next step is the familiarization with the experimental vehicle with the Alternative SkidCar, where experimental measurements were carried out, assessment of the advantages and disadvantages of the experimental vehicle with the Alternative SkidCar and the drive on the sliding surface following the experimental test methods. The objective of the article is to determine how great the difference in vehicle behaviour is when the adhesive force changes by modifying the radial reaction and the change in the coefficient of adhesion.

Keywords: Adhesive force, Experimental measurement, Skid of the vehicle, Vehicle stability

\section{The adhesive force of the road vehicle and possibilities for its modifications}

The magnitude of the adhesive force transmitted between the tire of the road vehicle and the road surface may be varied by changing the coefficient of adhesion or by changing the radial reaction transmitted by the vehicle's wheel $[1,2]$. In this article, we discussed reducing the adhesive force of an experimental vehicle so that we can put the vehicle in a skid at the socalled safe speed. The requirement to bring the vehicle to the skid at low - safe speed was triggered by the demands on the department. At the same time, the area of vehicle testing can be transferred from the experimental environment to the software environment $[3,4]$ where simplifying conditions need to be appropriately chosen.

\subsection{SkidCar system}

The producer is Cedergrens Klintehamn Sweden [5]. It is an electro-hydraulic wheel frame which allows the vehicle to achieve different adhesion conditions. The frame is attached to the car and with an electronically controlled hydraulic circuit it allows the front axle or rear axle or both axles to be partially unloaded at the same time, in any range. On a closer look at the frames offered, we found that SkidCar can only be used on selected vehicles. That is why we have approached designing a frame for the experimental vehicle. Since we have made adjustments to the frame over a commercially available system, we use the name the Alternative SkidCar. The main difference is in the mechanical way of changing the radial reaction of the vehicle's wheels. At the same time, we have placed the front wheels of an Alternative SkidCar behind the front axle axis of the vehicle as shown in Figure 1. In this way, we have achieved that the vehicle body is easier to pitch than with the commercial SkidCar.

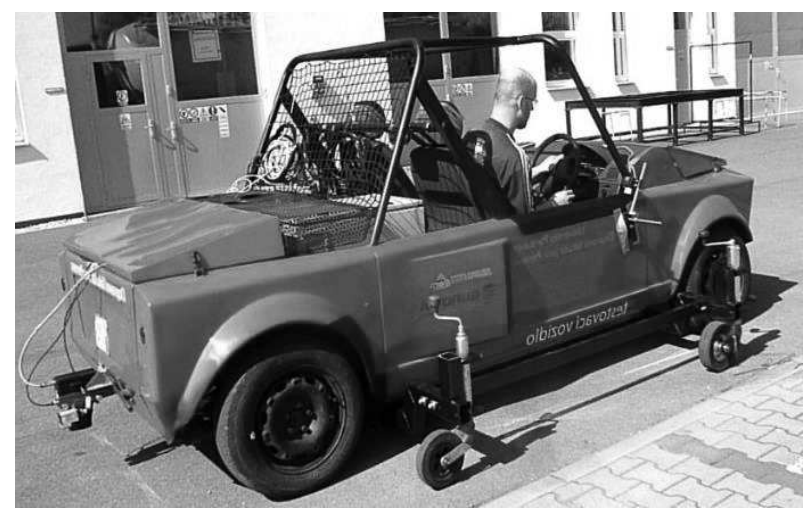

Fig. 1 Experimental vehicle with the Alternative SkidCar

The frame of the Alternative SkidCar system consists of two cross members, two side members and wheel units and is designed as detachable. The crossmembers are provided with mounts to secure the frame from below to the frame of the experimental car. At the ends of the cross members are a pair of clamps to which the guide tubes of the wheel units are attached. These wheel units are equipped with axial bearings that allow them to rotate freely around the vertical axis. Once mounted, the wheel units can be pushed out mechanically and thereby reduce the load of the wheels of the experimental car. The side members are mounted on both sides between the cross members, thereby increasing the rigidity of the entire structure, especially in the longitudinal direction. The frame of the Alternative SkidCar is designed without any optimization. For the purpose of future use, it is advisable to optimise the frame in terms of design $[6,7]$ and, if necessary, materials.

Advantages:

- continuously adjustable traction for any axle, 
- the possibility of altering the adhesive conditions when driving,

- reliable with minimal wear

- the possibility of holding an adhesive setting for repeatable tests,

- can be used on vehicles with front, rear and both drive axles,

- almost impossible to turn over a car,

- keeps the electronic systems of the car in operation,

- the road does not contain any optical or other information relating to the variation in the adhesive conditions,

- the possibility of using any tire,

- the repeatability of the adhesion conditions during the various tests is ensured.

Disadvantages:

- the system cannot be used on any car,

- the electro-hydraulic unit and solenoids can be heard operating in the vehicle, so the driver is warned that the adhesive conditions have changed,

- increase in the mass of the car and decrease of the height of the car's centre of gravity,

- the need for a relatively flat surface of sufficient size according to the considered test,
- the vehicle is equipped on the sides with auxiliary wheels - greater width of the tested vehicle means a negative property during manoeuvres,

- The body of the car is attached to the SkidCar frame - it is not possible to tilt the sprung masses in relation to the unsprung masses, the body does not tilt or roll during manoeuvres,

- the change in rolling resistance and the directional characteristics of the wheel tire due to a reduction in the radial reaction transmitted by the wheel.

\subsection{Skid surface}

There is essentially a section of asphalt with a special coating or a sliding foil that, when coated with a water, modifies its adhesion coefficient in a way similar to the sliding film. The skid surface (Figure 2) can be positioned both in a straight line and in a bend, as required for a road test. The skid surface may be made in the form of a continuous surface, possibly with alternating elements with a higher and lower coefficient of adhesion. These sub-areas may be made in the form of belts (transverse or longitudinal to the vehicle) or in the form of a chessboard, where the wheels of the same axle are at any given moment at different adhesion coefficients [8-10].

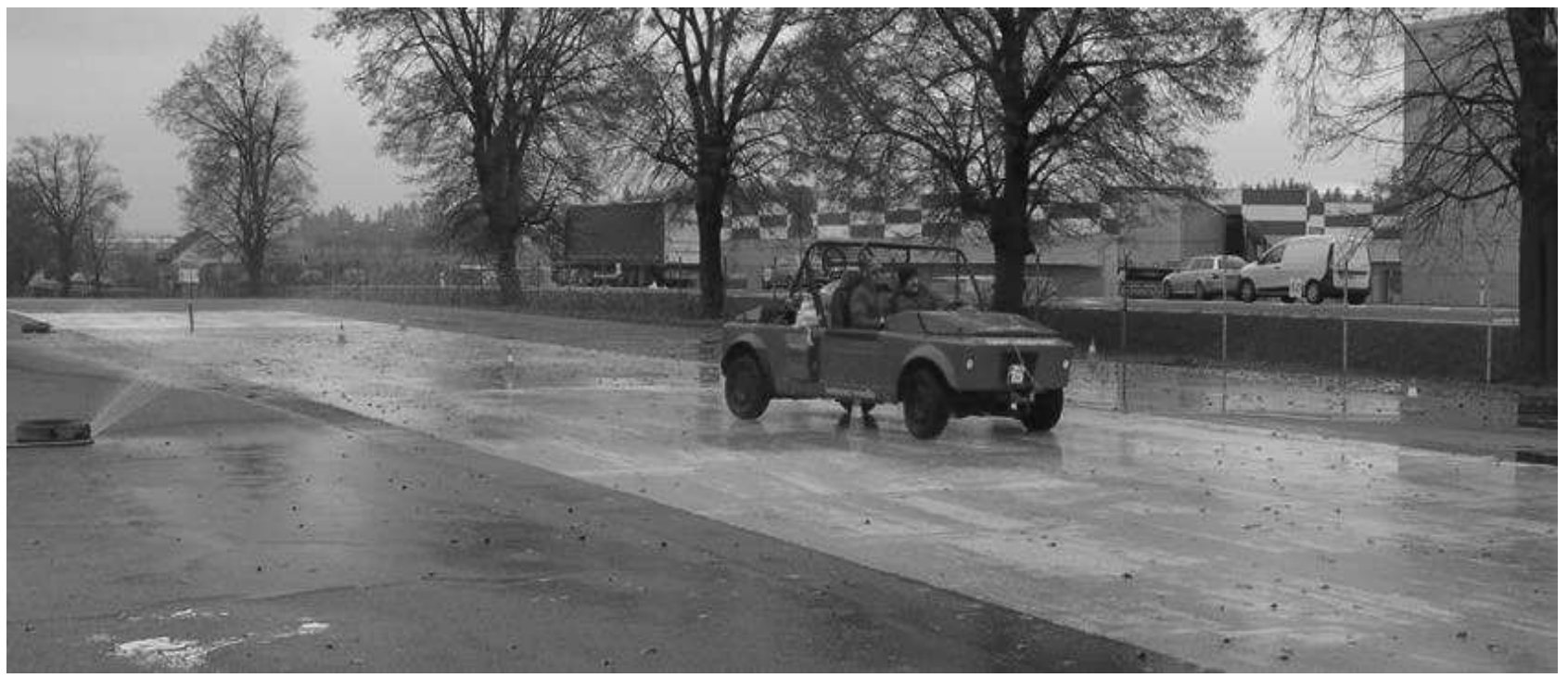

Fig. 2 An experimental vehicle on a skid surface

Advantages:

- the road conditions are very close to real conditions,

- the vehicle's dimensional and weight parameters are not changed,
- can be used on vehicles with front, rear and both drive axles,

- zero car adjustments,

- the applicability of any serial car or prototype,

- the possibility of using any tire, 
- to a certain extent, repeatability of the adhesion conditions during the various tests is ensured,

Disadvantages:

- the need for additional treatment of the test surface,

- the need to rebuild/replace the test surface,

- The possibility of carrying out tests only at temperatures above $+1{ }^{\circ} \mathrm{C}$,

- the need to ensure continuous water coating of the test area,

- the driver is able to identify a surface with different adhesion by visual perception,

- a smooth variation in the adhesive conditions is not possible,
- the exact value of the coefficient of adhesion,

- it is not possible to achieve a different coefficient of adhesion for each axle or wheel.

\section{Experimental measurements}

As a road test we have chosen a slalom test. The principle of the test is that the vehicle runs through a defined corridor between the cones at a predefined speed. For this speed, we choose the maximum speed at which the corridor on the sliding surface can be driven. The design of the corridor for the experimental test of the Alternative SkidCar and the driving test on the skid surface are shown in Figure 3. The driving tests for the Alternative SkidCar have been carried out for a $50 \%$ radial reaction to the vehicle wheels.
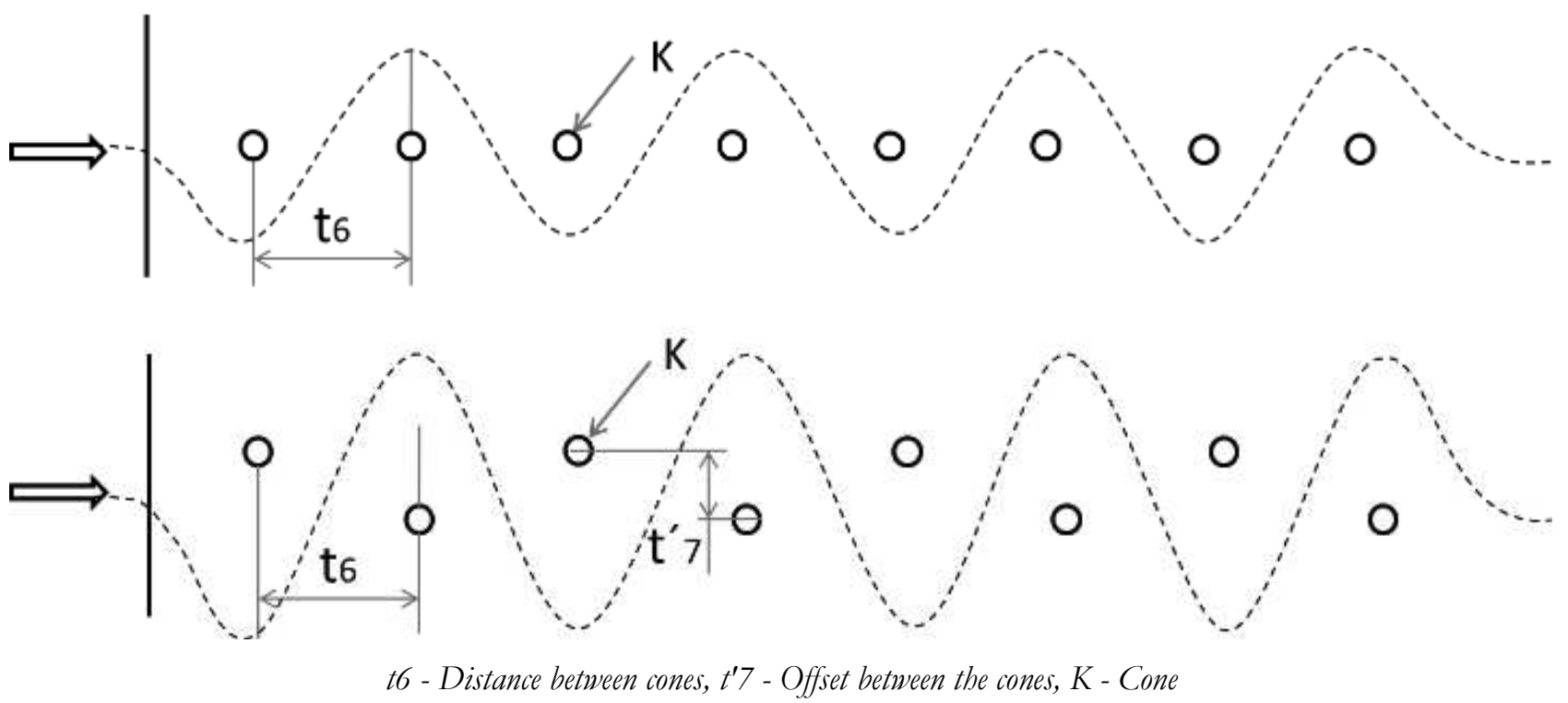

Fig. 3 Corridor for the slide test and the Alternative SkidCar

The speed $v$, tire slip angle $\varphi$ and the yaw rate of the vehicle $\omega$ were measured using the Correvit sensor. The steering wheel angle $\beta_{v}$ was detected via the analogue cable position sensor. Transverse $a_{y}$, and longitudinal $a_{x}$ acceleration using the acceleration sensor and the body roll angle $\beta_{i}$ by means of a pair of ultrasonic distance sensors located at the centre of gravity plane on the sides of the vehicle $[11,12]$.

To measure the characteristics of an experimental car, we have used a measuring system owned by the Educational and Research Centre in Transport, which we have complemented with steering wheel position sensor. We used the Correvit S-CE sensor to measure the speed of the vehicle, which simultaneously measures both components of the speed. Both the forward speed $v_{x}$ and the lateral speed $v_{y}$. To measure the yaw rate of a car we used the VG910S optical gyroscope, which is based on the Sagnac effect principle.
The gyro sensor of the yaw rate is part of the Correvit S-CE speed sensor. To measure the acceleration of the experimental vehicle during the driving tests we have used the 3-axis acceleration sensor iMEMS type ADXL311. The sensor was screwed firmly to the vehicle's central tunnel with the aid of a base plate. We measured the body pitch using a pair of HL2 and HP2 ultrasonic sensors. We have placed the HL2 sensor on the mount at the front of the vehicle and the HP2 sensor on a specially designed rear mount.

We calculated the body roll angle according to the formula (1), where $H_{3 i}\left(H_{4 i}\right)$ is the distance of the measuring point on the left (right) side of the body, at the prescribed distance from the road at time $t, B_{x}$ is the distance between the measuring points in the transverse plane of the vehicle, $H_{30}\left(H_{40}\right)$ is the distance from the measuring point to the ground corresponding to the steady speed of the vehicle [11]. 


$$
\beta_{i}=\tan ^{-1}\left(\frac{\left(H_{3 i}-H_{3 o}\right)-\left(H_{4 i}-H_{4 o}\right)}{B_{x}}\right)
$$

We compared the measured results to the experimental measurement on the skid surface.

\section{Evaluation of measured courses}

Time courses of the speed $v$, longitudinal acceleration $a_{x}$ and transverse acceleration $a_{y}$ are comparable in both tests, together with the steering angle $\beta_{\nu}$. There is an obvious difference in the height position of the HL1 axle lower right-hand arm, where the lift of the Alternative SkidCar is significantly limited by the use of the frame. A similar effect on body roll can be seen with the Alternative SkidCar in both HL2 and HP2 time courses. The difference in the body roll angle corresponds to the data measured by the height sensors, so the body roll of the Alternative SkidCar is negligible compared to the experimental vehicle. This is the most significant difference in measured courses.

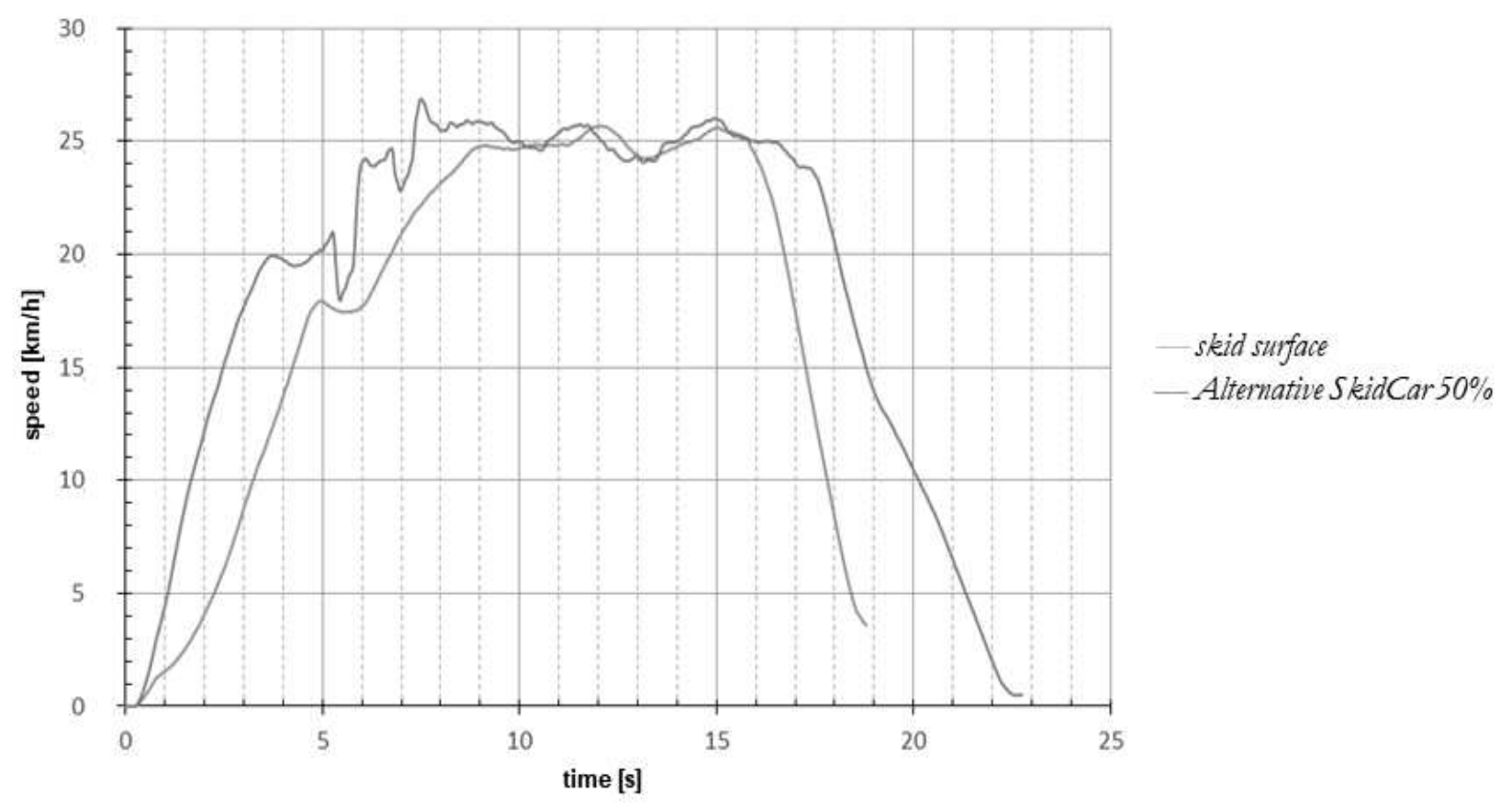

Fig. 4 Speed $v$ time course for the skid surface and the Alternative SkidCar

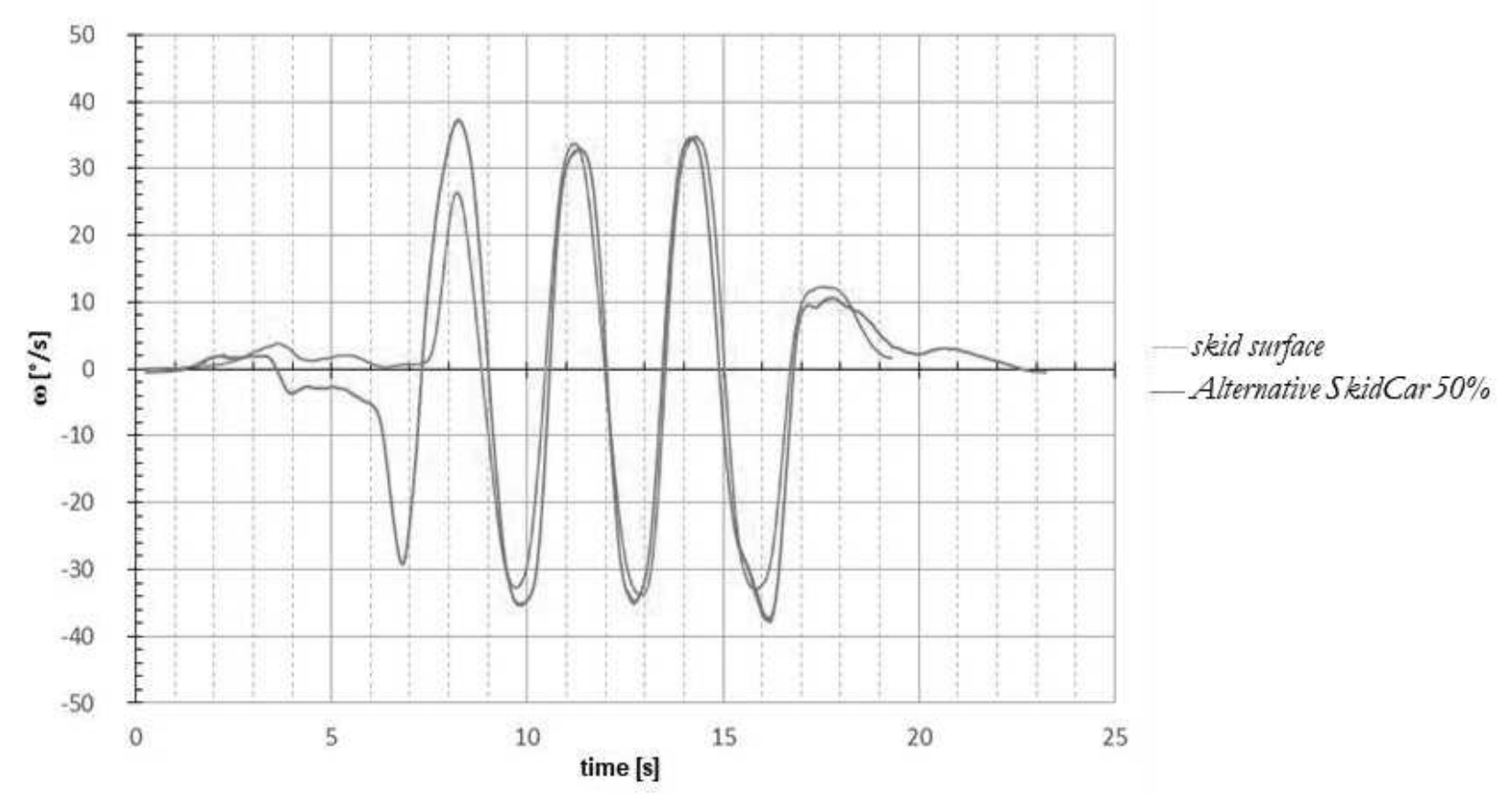

Fig. 5 Yaw rate time course $\omega$ for the skid surface and the Alternative SkidCar 


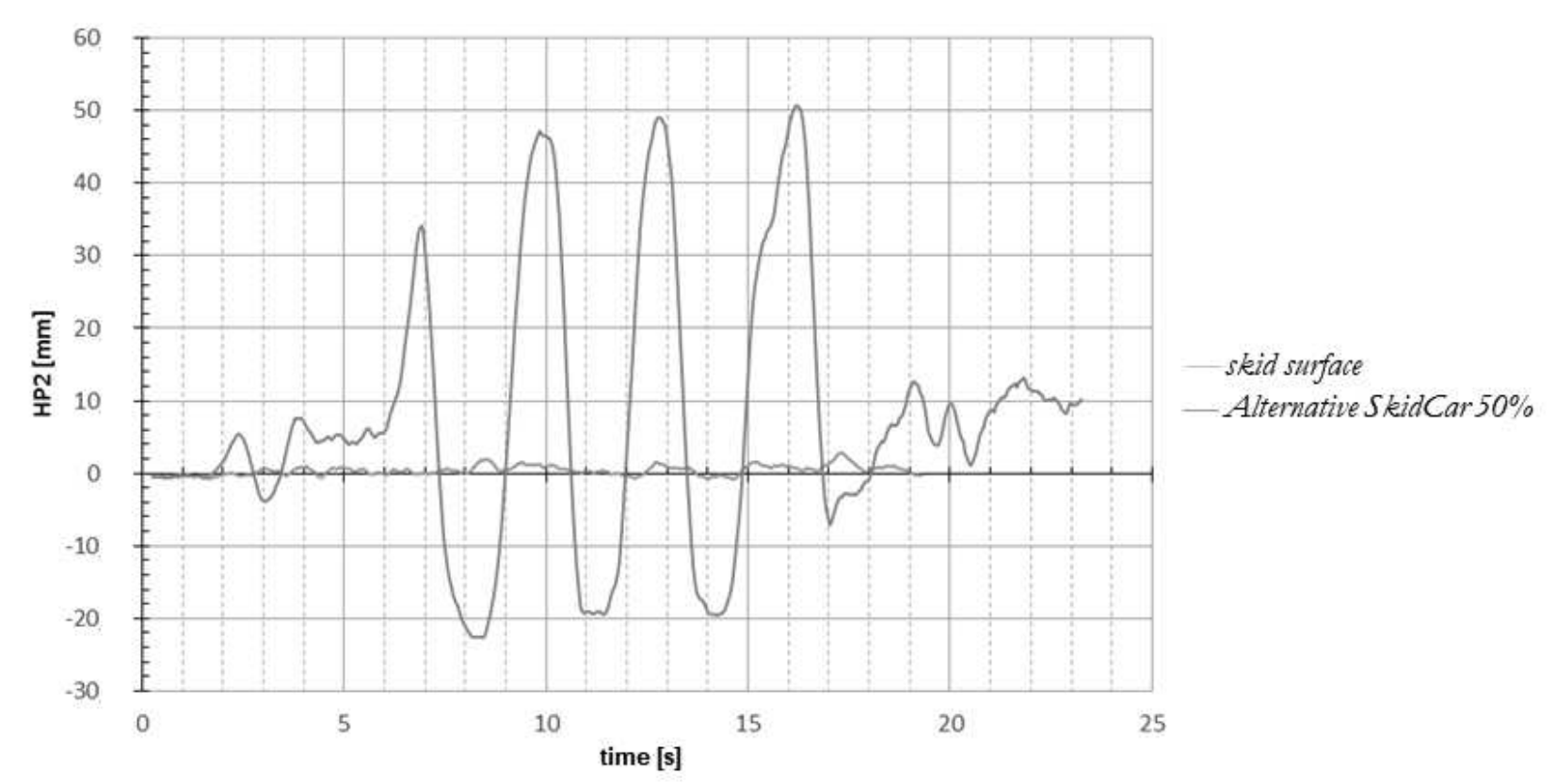

Fig. 6 Height coordinate time course of the HP2 right-hand side of the vehicle for the skid surface and the Alternative SkidCar

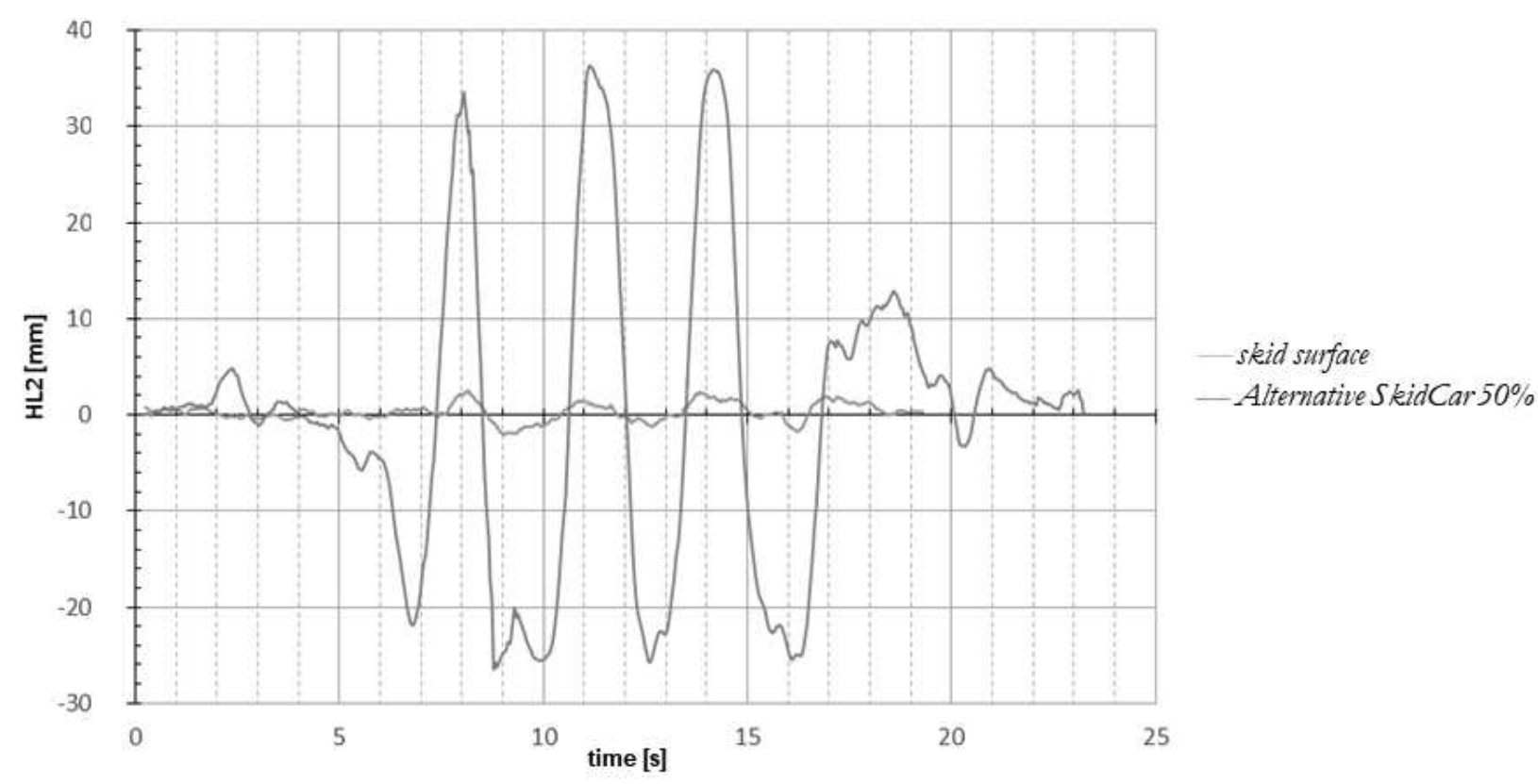

Fig. 7 Height coordinate time course of the HL2 left-hand side of the vehicle for the skid surface and the Alternative SkidCar

\section{Conclusion}

The measured time courses show that the Alternative SkidCar system allows to vary the adhesion force transmitted between the road vehicle and the road surface. The yaw rate time courses $\omega$ are comparable for sliding surface and the Alternative SkidCar. There is a big difference in the position of the body, where there is a more intense body roll on the skid surface than when using the Alternative SkidCar. The body roll limitation is caused by the attachment of wheeled units to the vehicle body via the subframe. The body roll magnitude of the Alternative SkidCar is determined by the tire stiffness of the support wheels.

From the measured data it is clear that any intervention in the structure of a road vehicle chassis has an effect on the behaviour of the vehicle as a result. Therefore, the Alternative SkidCar system also affects the behaviour of the car and thus it depends on the purpose of achieving an adhesion force reduction on the road vehicle wheels. Despite the fact that the Alternative SkidCar system causes some characteristics describing the behaviour of the vehicle to change, it is usable for the needs of the department and has met the desired objective. 


\section{References}

[1] NOVIKOV, I., LAZAREV, D. (2017). Experimental Installation for Calculation of Road Adhesion Coefficient of Locked Car Wheel, 12th international conference - organization and traffic safety management in large cities spbotsic-2016, St Petersburg, Russia, 20, 463 467.

[2] ONAT, A., VOLTR, P. (2020). Particle swarm optimization-based parametrization of adhesion and creep force models for simulation and modelling of railway vehicle systems with traction. Simulation modelling practice and theory, 99, 156-163.

[3] KLIMENDA, F., SVOBODA, M., RYCHLIKOVA, L., PETRENKO, A. (2015). Investigation of Vertical Vibration of a Vehicle Guide Driving Through a Horizontal Curve, Manufacturing Technology ISSN 1213-2489 vol. 15, pp 143-148

[4] SEGLA, Š., KAMPO, J. (2018). The Role of Modelling of Road Unevenness's in Vehicle Dynamics, Manufacturing Technology, Vol. 18, No. 1 pp. 124-129, ISSN: 1213-2489]

[5] JILEK, P., ŠEFČÍK, I., VERNER, J., BERG, J. (2019). System allowing adhesion force change of road vehicle, $18^{\text {th }}$ International Scientific Conference Engineering for Rural Development, Jelgava, Latvia, pp. 1876-1882.

[6] BAKOŠOVÁ A., KRMELA J., HANDRIK M. (2020). Computing of truss structure using
MATLAB. Manufacturing Technology ISSN 12132489, vol. 20 (3), pp. 279-285.

[7] SÁGA, M., VAŠKO, M., HANDRIK, M., KOPAS, P. (2019). Contribution to random vibration numerical simulation and optimisation of nonlinear mechanical systems. In: Scientific Journal of Silesian University of Technology. Series Transport, vol. 103, pp. 143-154.

[8] SONG, B. (2013). Cooperative lateral vehicle control for autonomous valet parking. International journal of automotive technology, vol.14 (4), pp. 633-640.

[9] JÖRNSEN, R., HELMUT, S. (2001). The automotive chassis engineering principles: chassis and vehicle overall, wheel suspensions and types of drive, axle kinematics and elastokinematics, steering, springing, tyres, construction and calculations advice. 2nd ed. Oxford: Butterworth Heinemann. ISBN 07-506-5054-0

[10] KRMELA, J. (2008). Computational modelling of tyres considering operating and safety requirements. Communications. Scientific Letters of the University of Žilina. Žilina. ISSN 1335-4205.

[11] JILEK, P., NĚMEC J. (2021). System for changing adhesion conditions in experimental road vehicle. International journal of automotive technology, ISSN:1229-9138, vol. 22(3), pp. 779-785.

[12] CABAN, J. , TURSKI, A., NIEOCZYM, A., TARKOWSKI, S., JEREB, B. (2019). Impact of specific factors on the state of the tire pressure value. The Arcbives of Automotive Engineering - Archiwum Motoryzacji, eISSN: 2084-476X, vol. 85(3), pp. 137-148. 